\title{
Long-term impact of developing a postoperative pulmonary complication after lung surgery
}

\author{
Sebastian T Lugg, ${ }^{1}$ Paula J Agostini, ${ }^{2,3}$ Theofano Tikka, ${ }^{2}$ Amy Kerr, ${ }^{2}$ Kerry Adams, ${ }^{2}$ \\ Ehab Bishay, ${ }^{2}$ Maninder S Kalkat, ${ }^{2}$ Richard S Steyn, ${ }^{2}$ Pala B Rajesh, ${ }^{2}$ \\ David R Thickett, ${ }^{1}$ Babu Naidu ${ }^{1,2}$
}

${ }^{1}$ Centre for Translational Inflammation Research (CITR), University of Birmingham, Queen Elizabeth Hospital Birmingham, Birmingham, UK ${ }^{2}$ Department of Thoracic Surgery, Heart of England NHS Foundation Trust, Bordesley Green East, Birmingham, UK ${ }^{3}$ School of Sport, Exercise and Rehabilitation Sciences, University of Birmingham, Birmingham, UK

\section{Correspondence to} Babu Naidu, Centre for Translational Inflammation Research (CTIR), University of Birmingham, Queen Elizabeth Hospital Birmingham, Birmingham B15 2GW, UK; b.naidu@bham.ac.uk

Received 13 August 2015 Revised 28 October 2015 Accepted 30 November 2015

\begin{abstract}
Introduction Postoperative pulmonary complications (PPC) such as atelectasis and pneumonia are common following lung resection. PPCs have a significant clinical impact on postoperative morbidity and mortality. We studied the long-term effects of PPCs and sought to identify independent risk factors.

Methods A prospective observational study involved all patients following lung resection in a regional thoracic centre over 4 years. PPCs were assessed daily in hospital using the Melbourne group scale based on chest X-ray, white cell count, fever, purulent sputum, microbiology, oxygen saturations, physician diagnosis and intensive therapy unit (ITU)/high-dependency unit readmission. Follow-up included hospital length of stay (LOS), 30-day readmissions, and mortality.

Results 86 of 670 patients (13\%) who had undergone a lung resection developed a PPC. Those patients had a significantly longer hospital LOS in days $(13,95 \% \mathrm{Cl}$ $10.5-14.9$ vs $6.3,95 \% \mathrm{Cl} 5.9$ to $6.7 ; p<0.001)$ and higher rates of ITU admissions ( $28 \%$ vs $1.9 \%$; $p<0.001$ ) and 30 -day hospital readmissions $(20.7 \%$ vs $11.9 \%$; $\mathrm{p}<0.05)$. Significant independent risk factors for development of PPCs were COPD and smoking $(p<0.05)$, not age. Excluding early postoperative deaths, developing a PPC resulted in a significantly reduced overall survival in months $(40,95 \% \mathrm{Cl} 34$ to 44 vs 46 , $95 \% \mathrm{Cl} 44$ to $47 ; p=0.006)$. Those who developed a PPC had a higher rate of non-cancer-related deaths ( $11 \%$ vs $5 \% ; p=0.020)$. PPC is a significant independent risk factor for late deaths in non-small cell lung cancer patients (HR 2.0,95\% Cl 1.9 to 3.2; $\mathrm{p}=0.006$ ).
\end{abstract}

Conclusions Developing a PPC after thoracic surgery is common and is associated with a poorer long-term outcome.

\section{BACKGROUND}

Lung cancer is the most common cause of cancer death within the UK. ${ }^{1}$ For those patients diagnosed with non-small cell lung cancer (NSCLC), potentially curative surgery is generally accepted as the most effective treatment. ${ }^{2}$ There is some evidence that patients with lung cancer in the UK present at a later stage and have a higher comorbidity than patients in some other European countries. ${ }^{3}$ Thus, surgical resection rates among those with proven NSCLC are lower in the UK (14\%) compared with central Europe (24\%). ${ }^{4} 5$ To address this, most

\section{Key messages}

What is the key question?

- Does the development of a postoperative pulmonary complication (PPC) following thoracic surgery for lung resection impact on long-term survival?

\section{What is the bottom line?}

- After excluding immediate postoperative deaths, developing a PPC is a significant independent risk factor for late deaths and these patients have a worse long-term survival.

\section{Why read on?}

- We demonstrate in our large prospective cohort that PPCs are common following thoracic surgery; the short-term and long-term effects of developing a PPC are striking; COPD and smoking are significant independent risk factors.

recent European and UK guidelines have widened the selection criteria for lung cancer surgery, ${ }^{6}$ which has helped improve resection rates. The 5 -year survival rates for lung cancer in the UK is poor $(9 \%)$ compared with central Europe (13\%) as demonstrated in the 1999-2007 EUROCARE-5 report. ${ }^{7}$ A more recent study has shown that cancer survival in England is improving, however continued investment is needed to close this international gap. ${ }^{8}$ Furthermore, while in-hospital mortality has fallen over the last three decades, mortality rates within the first 90 days of surgery are considerable. ${ }^{9}$ We need to understand the causes of these late complications if we are to improve long-term outcomes.

Lung cancer resection is also associated with a considerable risk of postoperative pulmonary complications (PPC), of which pneumonia and atelectasis are the most common. ${ }^{10}$ PPCs have a significant health and economic impact on patients and health care services. Indeed, as less fit patients are undergoing surgery, the incidence of PPCs is likely to increase further. The longer-term effects of developing a PPC in hospital following lung cancer surgery have not been defined. The identification of modifiable risk factors for PPCs has a 
crucial role in the development of innovative strategies to reduce the impact and incidence of PPCs. We hypothesise that PPCs are associated with the late postoperative mortality and morbidity observed following lung resection.

This study aims to assess the immediate and long-term impact of PPCs, and to identify potentially modifiable independent risk factors.

\section{METHODS}

This prospective observational study was conducted at a singlecentre large regional thoracic unit serving six million people. Consecutive patients who underwent open thoracotomy or video-assisted thoracoscopic surgery (VATS) for lung resection/ removal in a regional thoracic centre between April 2010 and April 2014 were observed. This study was conducted with the approval of the National Research Ethics Service (NRES) Committee West Midlands. This study was registered with the Birmingham Heartlands Hospital audit department (audit code 1672). Decisions regarding patient operability and resectability were informed by the British Thoracic Society guidelines for lung cancer resection. ${ }^{6}$

Patients were admitted to hospital on the day of surgery. All operations were performed with single lung ventilation under general anaesthesia, and patients were subsequently scheduled for extubation in the operating room. Postoperatively, patients were managed in a dedicated thoracic high-dependency unit (HDU) (level 2) and ward unless complications required their admission to the intensive therapy unit (ITU). Postoperative pain control was achieved by continuous thoracic epidural analgesia, paravertebral infusion, intrathecal morphine and/or intercostal blocks or systemic opioids (parenteral administration or intravenous patient-controlled administration). The choice of analgesic technique was made by the anaesthetist after discussion with the patient. From the first postoperative day, all patients had a daily physiotherapy programme comprising deep breathing exercises, incentive spirometry, supported coughing and mobilisation.

The Melbourne Group Scale (MGS) is a standardised scoring system validated by our group to define the presence of a PPC such as pneumonia or clinically significant atelectasis, which are likely to adversely affect the patient's clinical course. ${ }^{10}{ }^{11}$ Using this score, PPC is defined in those patients presenting with four or more of the following eight dichotomous factors: chest X-ray (CXR) findings of atelectasis or consolidation; raised white cell count (WCC) $\left(>11.2 \times 10^{9} / \mathrm{L}\right)$; temperature $>38^{\circ} \mathrm{C}$; signs of infection on sputum microbiology; purulent sputum differing from preoperative status; oxygen saturations $<90 \%$ on room air; physician diagnosis of pneumonia; and prolonged HDU stay or readmission to HDU or ITU for respiratory complications. The MGS was used daily by senior physiotherapists who were performing their routine respiratory assessments. The discharge criteria, agreed with investigators in advance included patients who were medically fit and who had been discharged from physiotherapy.

Data collected included demographics and preoperative record of smoking status, body mass index (BMI), percentage predicted FEV1, American Society of Anesthetist (ASA) score, subjective preoperative activity level and comorbidities including COPD defined by clinical diagnosis of the referring clinician and staged according to percentage predicted $\mathrm{FEV}_{1}$. Postoperative data included type of analgesia used and underlying pathology (including lung cancer staging if applicable). Total length of stay (LOS) was defined as the LOS in hospital after the date of surgery. The HDU and ITU LOS were also recorded, and ITU admission and 30-day readmission to hospital secondary to surgical or pulmonary complications. All patients were followed up for overall survival (OS) and the cause of death was obtained from the death certificate and hospital records. Deaths were classified as postoperative complication for patients who died within initial hospital admission or within 30 days of surgery, cancer related for those patients who died of disease progression/recurrence, and non-cancer related, or cause of death uncertain when records were not available or unclear.

\section{Statistical analysis}

Results are expressed as mean (SD or 95\% CI) for continuous variables and as a percentage for categorical variables. Univariate analyses of risk factors for development of PPCs were assessed by performing individual unadjusted logistic regression analysis and inclusion of one covariate at a time. Risk ratios with 95\% CI were generated for variables found to have statistically significant association with PPCs on univariate analysis. A backward multivariate binary logistic regression analysis was performed to identify the independent predictors of PPCs within this dataset.

The effect of PPCs on hospital, HDU and ITU LOS were assessed using the Mann-Whitney non-parametric test to accommodate for the presence of positive skewness. KaplanMeyer plots and the log-rank test were used to assess the impact of PPCs on survival. Cox regression was assessed including all risk factors in a model for long-term survival. All analyses were performed using the IBM SPSS V.20 and SAS 9.3 statistical package version (SAS Institute, Inc, Carry, North Carolina, USA).

\section{RESULTS}

There were 670 patients who underwent pulmonary resections during the study period; 377 of who were male $(56 \%)$. The mean \pm SD age of the group was $66.4 \pm 10.8$ years. Mean predicted FEV1 was $80.2 \pm 20.8 \%$, mean BMI $26.9 \pm 8.1 \mathrm{~kg} / \mathrm{m}^{2}$, 328 patients $(49 \%)$ had an ASA score $\geq 3,176$ patients $(26 \%)$ had COPD, 149 patients $(22 \%)$ were current smokers.

The most frequent procedure was lobectomy $(n=497,74 \%)$ followed by wedge or segmentectomy $(n=111,16 \%)$ and pneumonectomy $(n=37,5.5 \%)$. VATS lobectomy and segmentectomy were also performed $(n=54,8 \%$ and $n=8, \quad 1 \%$ respectively). Most common histological diagnosis was NSCLC $(n=477,71.2 \%)$ followed by benign disease $(n=73,11 \%)$ and metastatic disease of non-lung primary $(n=69,10.3 \%)$. Eighty-eight patients (13\%) had clinical evidence of a PPC using the MGS. The median day of this occurring was postoperative day 2. The four most common positive factors to trigger a score of 4 were raised WCC $(n=75,85 \%)$, purulent sputum $(n=72$, $82 \%)$, CXR findings $(n=69,78 \%)$ and reduced saturations $(n=68,77 \%)$.

On univariate analysis (table 1) the significant risk factors associated with developing a PPC were percentage predicted $\mathrm{FEV}_{1}$, ASA score $>3$ (risk ratio (RR) (4 vs 1) 4.11, 95\% CI 1.53 to 11 ), self-reported preoperative activity level $\leq 400 \mathrm{~m}$ (RR 1.8, 95\% CI 1.20 to 1.68), COPD diagnosis (RR 2.13, 95\% CI 2.45 to 15.01 ) and current smoking (RR (current vs never) $6.06,95 \%$ CI 2.57 to 3.40$)(p<0.05)$. Age, BMI, type of surgery (individually or collectively), VATS approach, cancer diagnosis or staging and cardiovascular disease were not significantly associated with development of PPC.

Using backward logistic regression to identify perioperative variables independently associated with PPCs, our multivariate 
Table 1 Baseline characteristics in PPC and non-PPC groups, including univariate analysis of risk factors associated with developing PPC

\begin{tabular}{|c|c|c|c|c|c|}
\hline Variables & Value & Total $(n=670)$ & PPC $(n=88)$ & Non-PPC $(n=582)$ & p Value \\
\hline Age & Mean $( \pm S D)$ & $66.4( \pm 10.8)$ & $67.1( \pm 9.6)$ & $66.4( \pm 11)$ & 0.547 \\
\hline $\mathrm{FEV}_{1} \%$ predicted & Mean $( \pm S D)$ & $80.2( \pm 20.8)$ & $75.8( \pm 20.7)$ & $80.94( \pm 20.7)$ & 0.034 \\
\hline $\mathrm{BMI}$ & Mean $( \pm S D)$ & $26.9( \pm 8.1)$ & $27.2( \pm 5.6)$ & $26.9( \pm 8.4)$ & 0.757 \\
\hline Gender & $\begin{array}{l}\text { Male } \\
\text { Female }\end{array}$ & $\begin{array}{l}377(66 \%) \\
293(44 \%)\end{array}$ & $\begin{array}{l}57(65 \%) \\
31(35 \%)\end{array}$ & $\begin{array}{l}320(55 \%) \\
262(45 \%)\end{array}$ & 0.086 \\
\hline ASA score & $\begin{array}{l}1 \\
2 \\
3 \\
4\end{array}$ & $\begin{array}{c}44(7 \%) \\
298(44 \%) \\
313(47 \%) \\
15(2 \%)\end{array}$ & $\begin{array}{c}5(6 \%) \\
32(36 \%) \\
44(50 \%) \\
7(8 \%)\end{array}$ & $\begin{array}{c}39(7 \%) \\
266(46 \%) \\
269(46 \%) \\
8(1 \%)\end{array}$ & 0.004 \\
\hline Preoperative activity level & $\begin{array}{l}\leq 400 \mathrm{~m} \\
>400 \mathrm{~m}\end{array}$ & $\begin{array}{l}185(27 \%) \\
465(73 \%)\end{array}$ & $\begin{array}{l}35(42 \%) \\
49(58 \%)\end{array}$ & $\begin{array}{l}150(27 \%) \\
416(73 \%)\end{array}$ & 0.005 \\
\hline Type of surgery & $\begin{array}{l}\text { Lobectomy } \\
\text { Subsegmentectomy/wedge } \\
\text { Pneumonectomy } \\
\text { Exploratory/biopsy } \\
\text { Sleeve } \\
\text { Chest wall }\end{array}$ & $\begin{array}{c}497(74 \%) \\
111(16 \%) \\
37(6 \%) \\
13(2 \%) \\
8(1 \%) \\
4(1 \%)\end{array}$ & $\begin{array}{l}64(73 \%) \\
15(17 \%) \\
3(3.5 \%) \\
3(3.5 \%) \\
2(2 \%) \\
1(1 \%)\end{array}$ & $\begin{array}{l}433(74 \%) \\
96(16.5 \%) \\
34(6 \%) \\
10(2 \%) \\
6(1 \%) \\
3(0.5 \%)\end{array}$ & 0.651 \\
\hline VATS & $\begin{array}{l}\text { Yes } \\
\text { No }\end{array}$ & $\begin{array}{c}62(9 \%) \\
608(91 \%)\end{array}$ & $\begin{array}{r}9(10 \%) \\
79(90 \%)\end{array}$ & $\begin{array}{c}53(9 \%) \\
529(91 \%)\end{array}$ & 0.735 \\
\hline Analgesia & $\begin{array}{l}\text { Epidural } \\
\text { Intrathecal morphine } \\
\text { Morphine Infusion } \\
\text { PCA } \\
\text { Paraverterbral } \\
\text { Other }\end{array}$ & $\begin{array}{c}254(38 \%) \\
146(22 \%) \\
63(9.5 \%) \\
50(7.5 \%) \\
146(22 \%) \\
5(1 \%)\end{array}$ & $\begin{array}{c}27(31 \%) \\
23(26 \%) \\
9(10 \%) \\
4(5 \%) \\
24(27 \%) \\
1(1 \%)\end{array}$ & $\begin{aligned} 227 & (39.4 \%) \\
123 & (21.4 \%) \\
54 & (9.3 \%) \\
46 & (8 \%) \\
122 & (21.2 \%) \\
& 4(0.7 \%)\end{aligned}$ & 0.443 \\
\hline Pathology & $\begin{array}{l}\text { NSCLC } \\
\text { Small cell LC } \\
\text { Carcinoid } \\
\text { Metastatic disease } \\
\text { Benign } \\
\text { Other }\end{array}$ & $\begin{array}{l}477(71.2 \%) \\
10(1.5 \%) \\
27(4 \%) \\
69(10.3 \%) \\
73(11 \%) \\
14(2 \%)\end{array}$ & $\begin{array}{c}64(73 \%) \\
3(3 \%) \\
4(4.5 \%) \\
6(7 \%) \\
11(12.5 \%) \\
0\end{array}$ & $\begin{array}{c}413(71 \%) \\
7(1 \%) \\
23(2 \%) \\
63(11 \%) \\
62(11 \%) \\
14(4 \%)\end{array}$ & 0.598 \\
\hline NSCLC staging & $\begin{array}{l}0 \\
\text { IA } \\
\text { IB } \\
\text { IIA } \\
\text { IIB } \\
\text { IIIA } \\
\text { IIIB } \\
\text { IV }\end{array}$ & $\begin{array}{c}5(1 \%) \\
120(26 \%) \\
112(24 \%) \\
94(20 \%) \\
53(11 \%) \\
77(16 \%) \\
5(1 \%) \\
4(1 \%)\end{array}$ & $\begin{array}{c}0 \\
13(22 \%) \\
10(17 \%) \\
14(23.3 \%) \\
9(15 \%) \\
13(22 \%) \\
0 \\
1(1.7 \%)\end{array}$ & $\begin{array}{c}5(1 \%) \\
107(26 \%) \\
102(25 \%) \\
80(20 \%) \\
44(11 \%) \\
64(16 \%) \\
5(1.3 \%) \\
3(0.7 \%)\end{array}$ & 0.762 \\
\hline COPD & $\begin{array}{l}\text { Yes } \\
\text { No }\end{array}$ & $\begin{array}{l}176(26 \%) \\
494(74 \%)\end{array}$ & $\begin{array}{l}38(43 \%) \\
50(57 \%)\end{array}$ & $\begin{array}{l}138(24 \%) \\
444(76 \%)\end{array}$ & $<0.001$ \\
\hline COPD severity & Mild $(<80)$ & $51(29 \%)$ & $12(32 \%)$ & $39(29 \%)$ & 0.904 \\
\hline (FEV ${ }_{1} \%$ predicted) & $\begin{array}{l}\text { Moderate }(50-80) \\
\text { Severe }(30-50)\end{array}$ & $\begin{array}{l}95(54 \%) \\
27(16 \%)\end{array}$ & $\begin{array}{r}19(61 \%) \\
6(16 \%)\end{array}$ & $\begin{array}{l}76(56 \%) \\
21(15 \%)\end{array}$ & \\
\hline IHD & $\begin{array}{l}\text { Yes } \\
\text { No }\end{array}$ & $\begin{array}{r}85(13 \%) \\
585(87 \%)\end{array}$ & $\begin{array}{l}15(17 \%) \\
73(83 \%)\end{array}$ & $\begin{array}{r}70(12 \%) \\
512(88 \%)\end{array}$ & 0.665 \\
\hline HTN & $\begin{array}{l}\text { Yes } \\
\text { No }\end{array}$ & $\begin{array}{l}279(42 \%) \\
391(58 \%)\end{array}$ & $\begin{array}{l}37(42 \%) \\
51(58 \%)\end{array}$ & $\begin{array}{l}242(42 \%) \\
340(58 \%)\end{array}$ & 0.934 \\
\hline Diabetes & $\begin{array}{l}\text { Yes } \\
\text { No }\end{array}$ & $\begin{array}{r}80(12 \%) \\
590(88 \%)\end{array}$ & $\begin{array}{l}14(16 \%) \\
74(84 \%)\end{array}$ & $\begin{array}{r}66(11 \%) \\
516(89 \%)\end{array}$ & 0.220 \\
\hline Smoking status & $\begin{array}{l}\text { Current } \\
\text { Ex } \\
\text { Never }\end{array}$ & $\begin{array}{l}149(22 \%) \\
391(68.5 \%) \\
129(22.5 \%)\end{array}$ & $\begin{array}{c}35(40 \%) \\
48(54 \%) \\
5(6 \%)\end{array}$ & $\begin{array}{l}114(20 \%) \\
343(59 \%) \\
124(21 \%)\end{array}$ & $<0.001$ \\
\hline
\end{tabular}

ASA, American College of Anaesthetists; BMI, body mass index; HTN, hypertension; IHD, ischaemic heart disease; NSLC, non-small cell lung cancer; PCA, patient-controlled analgesia; PPC, postoperative pulmonary complication; VATS, video-assisted thoracoscopic surgery.

analysis included all variables. No significant interactions across any of the variables were found. Only COPD diagnosis and smoking status were associated with the development of a PPC (table 2). Patients who had COPD were 1.81 times more likely to develop a PPC compared with those without COPD (95\% CI 1.11 to $2.95 ; \mathrm{p}=0.017)$. Current smokers were 5.42 times more likely to develop a PPC than never smokers (95\% CI 1.99 to 14.76; $\mathrm{p}<0.001)$, and ex-smokers were 2.8 times more likely to develop a PPC than never smokers (95\% CI 1.08 to 7.28; $\mathrm{p}=0.035)$. The goodness-of-fit test of this model remained nonsignificant during these steps, with a $\mathrm{p}$ value very close to one showing a very good model fit (Hosmer and Lemeshow $\mathrm{p}=0.975)$. The overall predictive power of the model was $66.3 \%$ indicated by the area under the curve (receiver operating characteristic (ROC)). The resulting logistic model had a sensitivity of $60.2 \%$ and a specificity of $65.9 \%$, with the cut-off probability point set at 0.12 . So in our model, a probability of more than 0.12 means that a patient has $60.2 \%$ possibility of 
Table 2 Preoperative risk factors associated with PPC on multivariate analysis

\begin{tabular}{lrrrll}
\hline Variables & Estimate & SE & $\mathbf{p}$ Value & OR & 95\% Cl \\
\hline Constant & -3.18 & 0.45 & $<0.001$ & \multicolumn{1}{l}{$l$} & \multicolumn{1}{l}{} \\
COPD & 0.59 & 0.25 & 0.017 & 1.81 & 1.11 to 2.95 \\
Current smoker (vs never) & 1.69 & 0.51 & $<0.001$ & 5.42 & 1.99 to 14.76 \\
Ex smoker (vs never) & 1.03 & 0.49 & 0.035 & 2.80 & 1.08 to 7.28 \\
\hline
\end{tabular}

PPC, postoperative pulmonary complication.

having a PPC. When the yielded probability is less than 0.12 , patients have $65.9 \%$ chance of not developing a PPC. The sensitivity of the model is the percentage of the group accurately identified by the model as having a PPC and the specificity is the percentage correctly identified as not having one.

Patients in the PPC group had a significantly longer (days) hospital LOS $(12.7,95 \%$ CI 10.5 to 14.9 vs 6.3 , $95 \%$ CI 5.9 to $6.7 ; \mathrm{p}<0.001)$, longer HDU LOS $(4.2,95 \%$ CI 3.4 to 4.9 vs $1.9,95 \%$ CI 1.8 to $2.1 ; \mathrm{p}<0.001)$ and longer ITU LOS $(2.1$, $95 \%$ CI 1.0 to 3.3 vs $0.2,95 \%$ CI 0.1 to $0.4 ; \mathrm{p}<0.001)$. In the PPC group there were higher rates of ITU admissions (28\% vs $1.9 \% ; \mathrm{p}<0.001$ ) (figure 1 , table 3). The 30-day hospital readmission was higher in the PPC group $(21 \%$ vs $12 \%$; $\mathrm{p}=0.023)$. Patients who developed a PPC in hospital had a higher rate of readmission secondary to pneumonia or lower respiratory tract infections $(9.1 \%$ vs $3.8 \% ; \mathrm{p}=0.046)$.

Of all patients, there were $176(26 \%)$ deaths with a median follow-up of 12 months (95\% CI 9.4 to 14.6). Causes of death included early postoperative complications (8.5\%), cancerrelated deaths (65\%), non-cancer-related deaths (21\%) and cause of death uncertain (5\%). Patients with a PPC had a significantly higher 30 -day $(9 \%$ vs $0.7 \% ; \mathrm{p}<0.001)$ and 90 -day mortality $(17 \%$ vs $2.9 \%$; $<<0.001)$.

Excluding patients who died of a postoperative complication $(15 / 670,2 \%)$, those who developed a PPC had a reduced OS with a mean follow-up of 40 months (40, 95\% CI 34.1 to 43.8

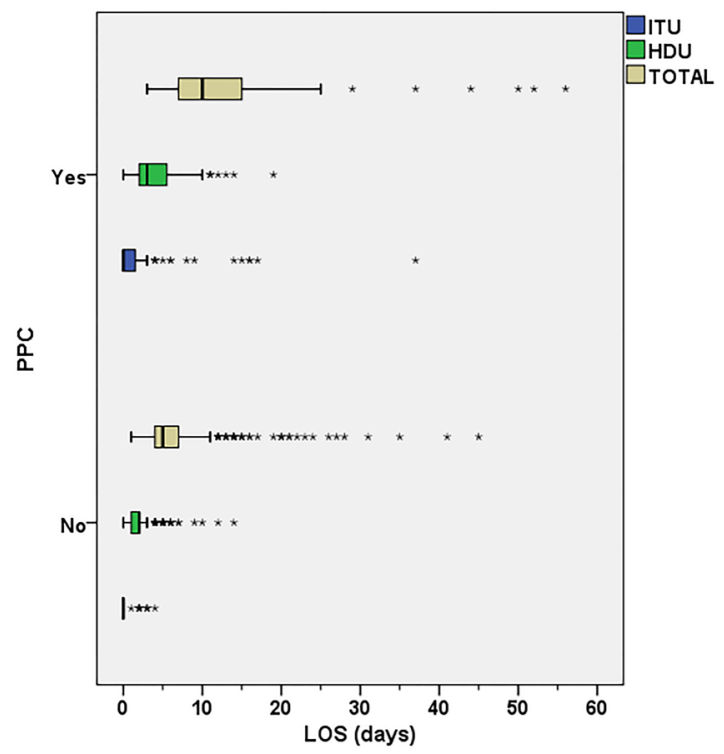

Figure 1 Effect of PPC on hospital length of stay (days). HDU, high-dependency unit; ITU, intensive treatment unit; LOS, length of stay; PPC, postoperative pulmonary complication; TOTAL; total length of hospital stay. vs $45.8,95 \%$ CI 44.3 to $47.3 ; \mathrm{p}=0.006$ ) (figure 2 ). There was a significantly increased number of non-cancer-related deaths in those who developed a PPC $(11 \%$ vs $5 \% ; p=0.020)$, of which patients who developed a PPC were significantly more like to die of non-malignant respiratory disease $(6.8 \%$ vs $2.2 \%$; $\mathrm{p}=0.028)$. Significant independent risk factors for late deaths in patients with NSCLC were PPCs (Cox regression: HR 2.00, 95\% CI 1.19 to $3.20 ; \mathrm{p}=0.005$ ), cancer stage, age and 30 -day readmission to hospital (table 4 ).

\section{DISCUSSION}

Our study confirmed that PPCs are common in thoracic surgery. The short-term morbidity of developing a PPC following thoracic surgery is striking, with significantly longer hospital, ITU and HDU LOS, higher frequency of ITU admissions and higher frequency of hospital readmissions secondary to pulmonary infections. Furthermore, patients who develop a PPC have a significantly increased mortality, in the early and late stages following surgery. After excluding immediate postoperative deaths, developing a PPC is a significant independent risk factor for late deaths and these patients have a worse long-term survival. Furthermore, we observed a high rate of non-cancer-related deaths in this cohort.

The frequency of PPCs observed at this regional thoracic surgery unit $(13 \%)$ is concurrent with other studies. ${ }^{10-15}$ The incidence of PPCs following thoracic surgery ranges between studies predominantly because there is no standard; it is

Table 3 Morbidity and mortality following the development of a PPC

\begin{tabular}{|c|c|c|c|}
\hline Variables & PPC $(n=88)$ & $\begin{array}{l}\text { Non-PPC } \\
(n=582)\end{array}$ & $\mathrm{p}$ Value \\
\hline Number of ITU admissions & $25(28 \%)$ & $11(1.9 \%)$ & $<0.001$ \\
\hline \multicolumn{4}{|l|}{ Mean LOS (95\% CI) (days) } \\
\hline Hospital & $12.7(10.5$ to 14.9$)$ & 6.3 (5.9 to 6.7$)$ & $<0.001$ \\
\hline HDU & $4.2(3.4$ to 4.9$)$ & 1.9 (1.8 to 2.1$)$ & $<0.001$ \\
\hline ITU & 2.1 (1.0 to 3.3$)$ & $0.2(0.1$ to 0.4$)$ & $<0.001$ \\
\hline \multicolumn{4}{|c|}{ Number of 30-day hospital readmissions } \\
\hline Total & $18(21 \%)$ & $67(12 \%)$ & 0.023 \\
\hline Pneumonia/LRTI & $8(9 \%)$ & $22(4 \%)$ & 0.046 \\
\hline $\begin{array}{l}\text { Postoperative } \\
\text { complication }\end{array}$ & $10(11 \%)$ & $43(7 \%)$ & 0.198 \\
\hline Uncertain & 0 & $2(0.3 \%)$ & 0.754 \\
\hline \multicolumn{4}{|l|}{ Number of deaths } \\
\hline Total & $37(42 \%)$ & $139(24 \%)$ & $<0.001$ \\
\hline 30-day mortality & $8(9 \%)$ & $4(0.7 \%)$ & $<0.001$ \\
\hline 90-day mortality & $15(17 \%)$ & $16(3 \%)$ & $<0.001$ \\
\hline \multicolumn{4}{|l|}{ Cause of death } \\
\hline $\begin{array}{l}\text { Postoperative } \\
\text { complication }\end{array}$ & $9(10 \%)$ & $6(1 \%)$ & $<0.001$ \\
\hline $\begin{array}{l}\text { Excluding postoperative } \\
\text { complication }\end{array}$ & $28(32 \%)$ & $133(22 \%)$ & 0.017 \\
\hline Cancer related & $18(20 \%)$ & $97(17 \%)$ & 0.380 \\
\hline \multicolumn{4}{|l|}{ Non-cancer related } \\
\hline Total & $10(11 \%)$ & $27(5 \%)$ & 0.020 \\
\hline Respiratory & $6(6.8 \%)$ & $13(2.2 \%)$ & 0.028 \\
\hline Cardiovascular & $3(3.4 \%)$ & $10(1.7 \%)$ & 0.395 \\
\hline Other & $1(1.1 \%)$ & $4(0.7 \%)$ & 0.507 \\
\hline Uncertain & 0 & $9(1.5 \%)$ & 0.615 \\
\hline
\end{tabular}

Lugg ST, et al. Thorax 2016;71:171-176. doi:10.1136/thoraxjnl-2015-207697 


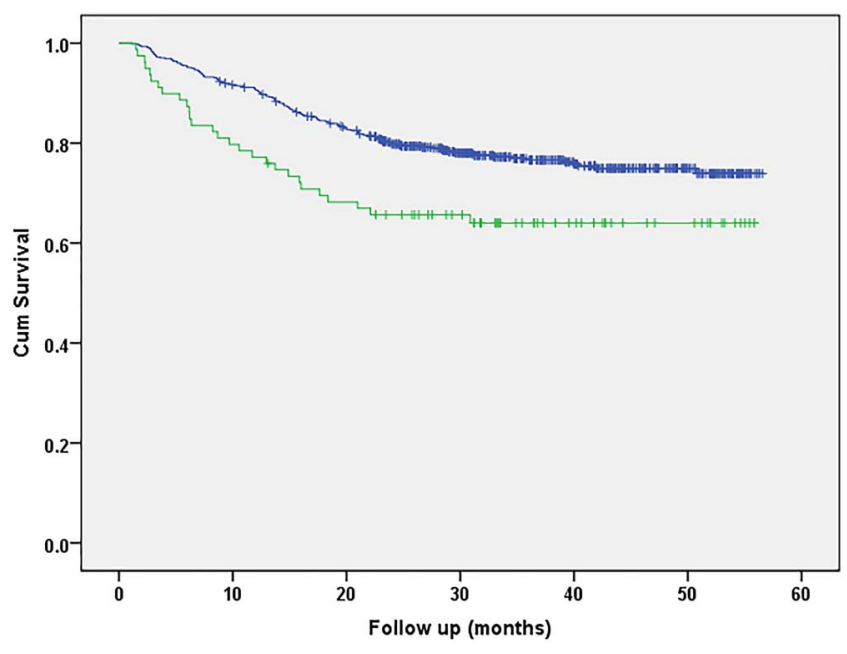

Figure 2 Overall survival of patients with and without a PPC excluding early postoperative deaths. Black line: no PPC; grey line: PPC. PPC, postoperative pulmonary complication.

dependent on the type of complications included, the definition of pulmonary complications, and the type of surgery. Use of the objective MGS to define a PPC does not include rare but serious postoperative complications such as broncho-pleural fistulas, which required re-operation in $0.4 \%$ of our patients, and also PE, which has been described in $2 \%$ of patients after thoracic surgery. ${ }^{16}$ However, the fact that those more frequent and probably less severe PPCs detected by the MGS were still associated with a higher short-term and long-term mortality rate is an important message.

Patients who develop a PPC are more than twice as likely to be readmitted within 30 days of surgery, and nearly three times more likely to re-present with respiratory tract infections. Hospital readmission is not only a serious morbidity; we demonstrate it is also an independent risk factor for the late deaths observed in our study. Patients who are readmitted within 30 days of lung cancer surgery have been shown to have a sixfold increase in 90-day postoperative mortality. ${ }^{17}$ In our study the 90-day mortality was 2.6 times that of 30 -day mortality, compatible with other study findings. ${ }^{9} 18$ Thus, this increased mortality following thoracic surgery is not explained by immediate postoperative deaths alone; we hypothesised that PPCs have a role in these later observed deaths.

Our study has shown that PPCs are significantly associated with reduced OS following thoracic surgery for lung resection. There is a paucity of data on the impact of PPCs on long-term outcome in thoracic surgery. A retrospective study which

Table 4 Significant Independent risk factors for late deaths in patients with non-small cell lung cancer

\begin{tabular}{lccccc}
\hline Variables & Estimate & SE & $\mathbf{p ~ V a l u e ~}$ & HR & $95 \% \mathrm{Cl}$ \\
\hline PPC & 0.69 & 0.25 & 0.006 & 2.00 & 1.19 to 3.20 \\
Staging IIA/B & 1.07 & 0.22 & $<0.001$ & 2.92 & 1.89 to 4.56 \\
Staging IIIA & 1.28 & 0.25 & $<0.001$ & 3.60 & 2.20 to 5.85 \\
Staging IIIB & 1.91 & 0.61 & 0.002 & 6.72 & 1.61 to 18.90 \\
Age & 0.03 & 0.01 & 0.003 & 1.04 & 1.01 to 1.06 \\
Readmission (30 days) & 0.62 & 0.23 & 0.008 & 1.86 & 1.15 to 2.89 \\
\hline PPC, postoperative pulmonary complication. & & &
\end{tabular}

included patients aged 66-80 who have undergone a lobectomy for stage 1 NSCLC found that development of a PPC was associated with reduced 5 -year OS $(52.7$ vs $65.9 \%, \mathrm{p}<0.001)$ and was an independent risk factor for mortality (HR 1.46, 95\% CI 1.24 to 1.73$).{ }^{19}$ We have also shown that developing a PPC is an independent risk factor for late deaths, but in comparison, our study is not limited by any inclusion criteria other than national guidelines. ${ }^{6}$ This includes those patients who are older and have more advanced staging of cancer, which we and other authors have found to be additional independent risk factors for late deaths. $^{20} 21$

We demonstrate for the first time that after excluding immediate postoperative deaths, patients with a PPC are more likely to die of late non-cancer-related deaths. This compares to the outcome of patients who are admitted to hospital secondary to community-acquired pneumonia. These patients have an increased risk of subsequent pneumonia and mortality after discharge, and a substantial proportion of these deaths are due to non-malignant respiratory disease. ${ }^{22}$ Some of the late deaths in patients who developed a PPC were secondary to cardiovascular disease; indeed, there is increasing evidence that pneumonia is associated with increased risk of cardiovascular complications, which may be due to residual inflammation having a role in triggering procoagulant pathways in these individuals. ${ }^{23}$

COPD and current smoking were found to be independent risk factors in the development of PPCs in ours and other studies. ${ }^{1021}$ Our multivariate model for assessing risk factors has a c-index of 0.66 , therefore it cannot be used as a diagnostic/highly predictive tool as we would like a predictive power ideally more than $80-90 \%$. Nevertheless, our analysis identified factors having significant association with PPCs. Patients diagnosed with COPD have an increased risk of pneumonia and atelectasis after surgery. ${ }^{24} 25$ We found on univariate analysis that a lower preoperative $\mathrm{FEV}_{1}$ percentage predicted was associated with the development of a PPC, though on multivariate analysis $\mathrm{FEV}_{1}$ is not an independent risk factor, as previously demonstrated. ${ }^{10}$ In our study, carbon monoxide lung diffusion capacity (DLCO) was performed only in patients with limited exercise tolerance or lung volumes so data are limited. However, studies have shown DLCO not to be an independent risk factor for long-term survival following thoracic surgery for lung cancer. ${ }^{26}{ }^{27}$ Risk modification for patients with COPD would be through a pulmonary rehabilitation programme, ${ }^{28}$ which in thoracic surgery has shown encouraging results in reducing PPCs, ${ }^{29}$ but more robust studies are needed in this field.

Smoking is the biggest independent risk factor for developing PPCs; indeed our study has shown PPCs to be up to five times more common in current smokers compared with never smokers, similar to other study findings. ${ }^{30}$ Key mechanisms are likely to involve the effect smoking has on impairing the mucociliary escalator, ${ }^{31}$ and also the antimicrobial and proinflammatory functions of alveolar macrophages, which decreases further during anaesthesia and surgery. ${ }^{32}$ Risk modification would be in the form of smoking cessation; however the duration needed in order to reduce postoperative risk remains a debated topic and is a much-needed area of future research.

Independent risk factors for developing PPCs have previously been identified as smoking, advanced age ( $\geq 75$ years old), reduced mobility, ASA score $\geq 3$, cardiovascular comorbidity, COPD and BMI $>30 \mathrm{~kg} / \mathrm{m}^{2} .{ }^{10-14}$ Interestingly, BMI, age and ASA score were not significant risk factors for the development of PPCs in our study. Other investigators have found that obesity does not confer greater morbidity and mortality after 
lung resection. ${ }^{33}$ We have shown that age is not a predictive factor for development of a PPC. This is an important finding for the clinical community and is supported by other studies that show no significant difference in postoperative complications in patients over the age of $75 .^{2134}$

\section{Study strengths and limitations}

This is a real-life study involving consecutive patients undergoing thoracic surgery in a tertiary centre; our patient demographics and staging of cancer is comparable to national data. ${ }^{9}$ The main limitation of our study is the low number of VATS cases recorded. VATS lobectomy has since increased to one-third of all lobectomies carried out in the UK due to the perceived minimally invasive nature of the procedure with reduced complications. We have previously described that the PPC incidence in VATS cases seems to be lower. ${ }^{35}$ The data of this study precede the growth of VATS lobectomies; therefore, the majority of our lung resections over the time frame were done via thoracotomy. Within the latter half of the study, two of the five surgeons had started to perform an increasing number of VATS lobectomies $(35 \%)$ compared with the first half of the study period $(3.4 \%)$. The finding of the VATS approach, not to show a significant reduction in the incidence of PPCs, is most likely because of under powering. Further studies into the effects of transition of thoracotomy to VATS on PPC frequency and long-term outcome will need to be conducted. There is limitation with regards to the patient follow-up data; as information on mortality and cause of death were obtained from hospital records and death certificates in a retrospective manner, in a few patients cause of death could not be ascertained (5\%). Additionally, we did not follow up for cancer recurrence and therefore we could not assess the effect of PPCs on disease-free survival in patients with lung cancer, which would be an interesting area for further investigation.

\section{CONCLUSION}

In summary, developing a PPC after thoracic surgery is associated with a poorer long-term outcome. We have found COPD and smoking are independent risk factors for developing PPCs, while age was not a predictive factor. Further research is required into the effect of risk modification on the development of PPCs and subsequent long-term outcome following thoracic surgery.

Contributors STL carried out data collection and drafted the final manuscript. PJA, AK and KA carried out data collection. TT performed the statistical analysis. EB, MSK, PBR, RSS and BN were involved in patient selection for surgery. BN and DRT have critically reviewed the manuscript and given final approval of the version to be published. All authors read and approved the final manuscript.

Competing interests None declared.

Ethics approval The study received ethics approval by the National Research Ethics Service (NRES) Committee West Midlands, Edgbaston.

Provenance and peer review Not commissioned; externally peer reviewed.

\section{REFERENCES}

1 Office for National Statistics. Mortality Statistics: Deaths Registered in England and Wales (Series DR), 2013. http://www.ons.gov.uk/ons/rel/vsob1/mortality-statisticsdeaths-registered-in-england-and-wales--series-dr-/2013/index.html

2 Pearson FG. Current status of surgical resection for lung cancer. Chest 1994;106:337S-9S.

3 Imperatori A, Harrison RN, Leitch DN, et al. Lung cancer in Teeside (UK) and Varese (Italy): a comparison of management and survival. Thorax 2006;61:232-9.

4 Damhuis RA, Schutte PR. Resection rates and postoperative mortality in 7,899 patients with lung cancer. Eur Respir J 1996;9:7-10.

5 Rich AL, Tata LJ, Stanley RA, et al. Lung cancer in England: information from the National Lung Cancer Audit (LUCADA). Lung Cancer 2011;72:16-22.
6 Lim E, Baldwin D, Beckles M, et al., British Thoracic Society; Society for Cardiothoracic Surgery in Great Britain and Ireland. Guidelines on the radical management of patients with lung cancer. Thorax 2010;65(Suppl 3):iii1-27.

7 De Angelis R, Sant M, Coleman MP, et al. Cancer survival in Europe 1999-2007 by country and age: results of EUROCARE-5-a population-based study. Lancet Oncol 2014; 15:23-34

8 Walters S, Benitez-Majano S, Muller $\mathrm{P}$, et al. Is England closing the international gap in cancer survival? Br J Cancer 2015;113:848-60.

9 Powel H, Tata L, Baldwin D, et al. Early mortality after surgical resection for long cancer: an analysis of the English National Lung cancer audit. Thorax 2013;68:826-34.

10 Agostini P, Cieslik H, Rathinam S, et al. Postoperative pulmonary complications following thoracic surgery: are there any modifiable risk factors? Thorax 2010;65:815-8

11 Agostini P, Naidu B, Cieslik H, et al. Comparison of recognition tools for postoperative pulmonary complications following thoracotomy. Physiotherapy 2011;97:278-83

12 Stéphan F, Boucheseiche S, Hollande J, et al. Pulmonary complications following lung resection: a comprehensive analysis of incidence and possible risk factors. Chest 2000;118:1263-70.

13 Brunelli A, Al Refai M, Monteverde $\mathrm{M}$, et al. Stair climbing test predicts cardiopulmonary complications after lung resection. Chest 2002;121:1106-10.

14 Bernard A, Deschamps C, Allen MS, et al. Pneumonectomy for malignant disease: factors affecting early morbidity and mortality. I Thorac Cardiovasc Surg 2001:121:1076-82.

15 Licker MJ, Widikker I, Robert J, et al. Operative mortality and respiratory complications after lung resection for cancer: impact of chronic obstructive pulmonary disease and time trends. Ann Thorac Surg 2006;81:1830-7.

16 Christensen TD, Vad $\mathrm{H}$, Pedersen $\mathrm{S}$, et al. Venous thromboembolism in patients undergoing operations for lung cancer: a systematic review. Ann Thorac Surg 2014;97:394-400.

$17 \mathrm{Hu}$ Y, McMurry TL, Isbell JM, et al. Readmission after lung cancer resection is associated with a 6-fold increase in 90-day postoperative mortality. J Thorac Cardiovasc Surg 2014;148:2261-7.

18 Pezzi CM, Mallin K, Medez AS, et al. Ninety-day mortality after resection for lung cancer is nearly double 30-day mortality. J Thorac Cardiovasc Surg 2014;148:2269-77.

19 Rueth NM, Parsons HM, Habermann EB, et al. The long-term impact of surgical complications after resection of stage 1 nonsmall cell lung cancer: a population-based survival analysis. Ann Surg 2011;254:368-74.

20 Camogeorgakis T, Anagnostopoulos CE, Connery CP, et al. Independent predictors for early and midterm mortality after thoracic surgery. Thorac Cardiovasc Surg 2007:55:380-4.

21 Sekine $Y$, Suzuki $H$, Yamada $Y$, et al. Severity of chronic obstructive pulmonary disease and its relationship to lung cancer prognosis after surgical resection. Thorac Cardiovasc Surg 2013;61:124-30.

22 Hedlund JU, Ortqvist $A B$, Kalin ME, et al. Factors of importance for the long term prognosis after hospital treated pneumonia. Thorax 1993:48:785-9.

23 Prina E, Ranzani OT, Torres A. Community-acquired pneumonia. Lancet 2015:386:1097-108.

24 Schussler 0 , Alifano $\mathrm{M}$, Dermine $\mathrm{H}$, et al. Postoperative pneumonia after major lung resection. Am J Respir Crit Care Med 2006:173:1161-9.

25 Stolz AJ, Schutzner J, Lischke R, et al. Predictors of atelectasis after pulmonary lobectomy. Surg Today 2008;38:987-92.

26 Guo X, Cao H, Xu J, et al. Forced vital capacity predicts long-term survival for curative-resected NSCLC. Med Oncol 2014;31:146.

27 Wang J, Olak J, Ferguson MK. Diffusing capacity predicts operative mortality but not long-term survival after resection for lung cancer. J Thorac Cardiovasc Surg 1999:117:581-6.

28 British Thoracic Society Standards of Care Subcommittee on Pulmonary Rehabilitation. Pulmonary rehabilitation. Thorax 2001:56:8270-334.

29 Bradley A, Marshall A, Stonehewer L, et al. Pulmonary rehabilitation programme for patients undergoing curative lung cancer surgery. Eur J Cardiothorac Surg 2013:44:266-71

30 Bluman LG, Mosca L, Newman N, et al. Preoperative smoking habits and postoperative pulmonary complications. Chest 1998;113:883-9.

31 Ramos EM, De Toledo AC, Xavier RF, et al. Reversibility of impaired nasal mucociliary clearance in smokers following a smoking cessation programme. Respirology 2011;16:849-55

32 Kotani N, Hashimoto $\mathrm{H}$, Sessler DI, et al. Smoking decreases alveolar macrophage function during anesthesia and surgery. Anesthesiology 2000;92:1268-77.

33 Mungo B, Zogg CK, Hooker CM. Does obesity affect the outcome of pulmonary resections for lung cancer? A National Surgical Quality Improvement Program analysis. Surgery 2015;157:792-800.

34 Cerfolio RJ, Bryant AS. Survival and outcomes of pulmonary resection for non-small cell lung cancer in the elderly: a nested case-control study. Ann Thorac Surg 2006:82:424-9.

35 Agostini $P$, Adams $K$, Kalkat $M$, et al. Is physiotherapy routinely required following video-assisted thoracoscopic surgery? Interact CardioVasc Thorac Surg 2013;17 (Suppl 2):S155-62. 